\title{
DESENVOLVIMENTO SUSTENTÁVEL E A SOCIEDADE DA INFORMAÇÃO: UMA PARCERIA NATURAL?
}

\author{
Ariadne C. FURNIVAL*
}

\begin{abstract}
RESUMO
Na forma de uma revisão da literatura, é examinada a hipótese de que o advento da chamada "sociedade pós industrial" ou "sociedade da informação" tem dado lugar a um período de atividade socio-econômico que representa uma mudança radical do modo anterior de desenvolvimento. É discutido o consenso de que a dinâmica desta nova forma de sociedade favorece um tipo de desenvolvimento econômico e social ecologicamente mais sustentável, principalmente porque o novo paradigma tem como seu eixo a informação e atividades relacionadas a ela, o que promoveria uma suposta "desmaterialização" da sociedade. A questão das formas com as quais este novo paradigma de desenvolvimento pode, ou não, afetar os chamados "países recém desenvolvidos" é também discutida.
\end{abstract}

Palavras-chave: desenvolvimento sustentável, sociedade de informação, desmaterialização.

\begin{abstract}
The study facuses, in the form of a literature review, the hypothesis that the advent of the so-called "post-industrial, information society" has moved to a period of socio-economic activity and development that represents a radical departure from the "old ways". Within this framework, it stresses the wide-held notion that the dynamics of this new mode of society favours a type of economic and social development that is ecologically more sustainable, principally because the new development paradigm centres on information and information-related activities. The question of the ways that this new development paradigm may or may not affect the socalled late developing countries is also addressed.
\end{abstract}

Keywords: sustainable development, information society, dematerialization.

INTRODUÇÃO

A publicação, em 1973, da obra The coming of post-industrial society, de Daniel Bell, pode ser vista como o momento em que as alegações do advento da "sociedade de informação" assumiram força. Isto porque a tese de Bell baseou-se no reconhecimento da centralidade da

(2) Profa. no Departamento de Ciência da Informação, Universidade Federal de São Carlos, Rodovia Washington Luiz, km 235, 13560-905, São Carlos, S.P. Brasil

E-mail: chloe@ power.ufscar.br 
informação, e dos setores de informação e serviços, à sociedade pós-industrial. Em comparação com as sociedades pré-industriais e industriais, nas quais, argumentou Bell, "raw muscle power" e a máquina são, respectivamente, os motores de progresso, nas sociedades pós-industriais, é a informação e o setor de serviços que predominam. A "sociedade de informação", para Bell, é marcada pela ascensão da importância dos intelectuais e do trabalho profissional em geral, que, por sua vez, acarretou a geração e circulação quantitativa e qualitativa de mais informação e conhecimento.

Na sua obra Theories of the information society (1995), Frank Webster questiona a afirmação de Bell de que o pós-industrialismo assinala uma "mudança sistêmica em relação a sociedades (agrícolas e industriais) anteriores"(1), assim como questiona a noção muito difundida do que o pós-fordismo e pós-modernismo também representam quebras qualitativas com o passado. O paradigma fordista tinha sido caracterizado pela disseminação de produção e consumo em massa, a ascensão do trabalhador industrial como uma feição constante da sociedade, e pelo Estado-Nação diretamente envolvido na economia, além de fornecendo o loco da atividade econômica. Em contraste, a consolidação do paradigma pós-fordista supostamente tem sido marcada pelo recuo da força de trabalho organizada ("organized labour") e pelo Estado, e pela decadência da produção e consumo em massa, cedendo lugar aos fenômenos de trabalho, produção e consumo flexíveis, incluindo a própria flexibilização do tempo e espaço. Toda essa flexibilidade está reforçada pelo overhaul radical dos sistemas de comunicação, financeiro, de produção e de mercado, e a globalização dos mesmos. Reconhecendo estas mudanças substanciais, poderíamos ser levados a acreditar, diz Webster (op.cit.), que a sociedade tem passado por mudanças radicais e qualitativas nas estruturas e relações sociais, metamorfoseando-se assim, numa sociedade pós-industrial e informacional. Mas Webster (op.cit.) argumenta que, pelo contrário, podemos detectar as continuidades na sociedade: a predominância continuada do critério do mercado, da produção de commodities, do trabalho assalariado ("wage labour"), propriedade privada, e, mais importante ainda, a consolidação e crescimento quase desenfreados das grandes corporações privadas, fortalecidas mais ainda por seu novo alcance global, facilitado pela expansão e interligação em rede dos sistemas mundiais de telecomunicações. Do mesmo modo, Webster (op.cit.) questiona as alegações dos teóricos de posmodernismo de que os fenômenos da usurpação dos discursos dominantes por aqueles que eram anteriormente marginalizados, da relativização de todas as afirmações definitivas da "Verdade", e da fragmentação do sujeito, são fenômenos que estão nos levando a uma sociedade qualitativamente distinta e pós-moderna, caracterizada por uma nova configuração de relações sociais. O que Webster admite, entretanto, é que entre todos esses "pós" (industrialismo, fordismo, modernismo), existe um papel central marcante para a informação e a infra-estrutura da informação na reestruturação da produção e consumo e das plataformas do mercado, mas que isto não deveria nos levar a acreditar que as relações sociais e a dinâmica social têm sido radicalmente alteradas. De forma parecida, Eric Hobsbawm ${ }^{(2)}$ nota que a "nova sociedade" não opera via destruição total que herdou da antiga, mas opera "adaptando de forma seletiva a herança do passado para seu próprio uso".

\section{A "DESMATERIALIZAÇÃO" E O PARADIGMA TECNO-ECONÔMICO DA INFORMAÇĀO E COMUNICAÇŌES}

A idéia da existência evidente de uma sociedade de informação atual nos leva a um outro conjunto de afirmações que se referem à existência das chamadas "sociedades desmaterializadas", as quais, por serem supostamente calcadas em economias de serviços que produzem menos bens materiais, estão rumos a modos de desenvolvimento ecologicamente mais sustentáveis.

Doze anos atrás, a Comissão Brundtland lançou o conceito de desenvolvimento sustentável no relatório da Comissão intitulado Nosso Futuro Comum (Our Common Future). A própria noção do que, exatamente, constitui "desenvolvimento sustentável" tem gerado muita polêmica, mas a definição mais conhecida e difundida, e talvez intuitivamente mais aceitável, é aquela que consta no relatório, que o define como sendo o processo de desenvolvimento que "atende às necessidades da 
geração atual sem comprometer a capacidade das gerações futuras de atender suas próprias necessidades." É uma visão de desenvolvimento, alegam seus defensores, que dá ênfase à necessidade de levar em consideração fatores políticos e culturais, muito diferente, então, do paradigma neoclássico de desenvolvimento econômico, que vê o desenvolvimento sustentável como sendo possível somente com taxas altas contínuas e "sustentáveis" de crescimento econômico e progresso técnico, baseado em valores de estilo de vida que têm origem no hemisfério norte. Foi Ignacy Sachs ${ }^{(3)}$ que chamou atenção às cinco dimensões de sustentabilidade que fazem parte de o que ele denominou "ecodesenvolvimento" (o conceito sobre o qual aquele de desenvolvimento sustentável foi construído), a saber: sustentabilidade social, sustentabilidade econômica, sustentabilidade ecológica, sustentabilidade espacial e sustentabilidade cultural.

O conceito de desenvolvimento sustentável da Comissão Brundtland também tem sido criticado por concentrar-se na questão "sustentável", sem esclarecer o que entende pelo termo "desenvolvimento"(4). Ribeiro ${ }^{(5)}$ elabora a questão, apontando o fato de que, desde o século dezenove, quando a integração crescente das economias mundiais iniciou-se, a ideologia de desenvolvimento, e todas as polaridades binárias que o termo evoca (desenvolvimento/subdesenvolvimento, avançado/ atrasado, Primeiro Mundo/Terceiro Mundo), satisfez uma necessidade de "dar significado às posições desiguais internas ao sistema $3 / 4$ sem requerer a dominação aberta dos tempos coloniais." A noção de desenvolvimento, então, se tornou uma meta supostamente neutra, almejada universalmente, que, na realidade, obriga as nações do mundo a uma corrida para alcançar metas fixadas pelas nações mais "desenvolvidas" (nas palavras de Celso Furtado, é uma corrida de "performance internacional”). Segundo alguns críticos do conceito de desenvolvimento sustentável, os defensores do conceito estão somente interessados em sustentar o modo de vida do Ocidente (que já causou muita destruição), promovendo como principal novidade a gestão mais eficiente dos custos sociais e ambientais das atividades de desenvolvimento. Outros críticos enfatizam que não é a sustentabilidade do desenvolvimento que deveria ser a meta, mas aquela da sociedade ("sustainable society”), que se caracterizaria principalmente por ser uma ordem social mais participativa ${ }^{(6,7)}$.

Apesar das críticas, já é perceptível que, nesta última década do século, as metas de desenvolvimento sustentável têm penetrado rapidamente o mainstream do discurso e processo de policymaking (formulação de políticas públicas) em todo nível, do local ao global. Este fato, em si mesmo, é otimista, dado a característica notória do desenvolvimento sustentável ser um "alvo em movimento contínuo" (moving target $)^{(8)}$, no sentido que os problemas ambientais são extremamente fluídos e estão em mudança contínua, especialmente com respeito a sua complexidade e escala.

Uma medida supostamente concreta do progresso de desenvolvimento sustentável é aquela da taxa com a qual uma dada sociedade "desmaterializa-se". Afirma-se que existe uma correlação direta entre a desmaterialização da economia de uma nação e a difusão penetrante nela, daquilo que Freeman e Perez ${ }^{(9)}$ denominaram o "paradigma tecno-econômico de ICT" (information and communications technology techno-economic paradigm). Uma mudança do paradigma tecno-econômico gera muitos impactos de longo alcance, principalmente porque tal mudança "não apenas leva ao surgimento de uma nova série de produtos, serviços, sistemas e indústrias por si mesmo; mas também afeta direta ou indiretamente quase todos os outros ramos da economia". Assim, o arraigamento de um novo paradigma tecno-econômico traz consigo as seguintes mudanças no sistema produtivo total ${ }^{(10)}$ :

“a) uma nova forma de organização de "melhor prática" (best practice) na firma e em nível de planta; b) um novo perfil de habilidades da força de trabalho, afetando ambos a qualidade e quantidade de mão-de-obra e padrões de distribuição de renda correspondentes; c) um novo "mix" de produtos no sentido que a escolha preferida para investimento recairia naqueles produtos que fazem uso intensivo de custo baixo, seu principal fator; d) novas tendências em ambos as inơvações radicais e incrementais que procuram substituir elementos relativamente custosos por um 
uso mais intensivo do(s) novo(s) fator(es) chav(es); e) um novo padrão do local de investimento nacional e internacional na medida em que as mudanças na estrutura de custos transforma as vantagens comparativas; f) uma onda particular de investimentos infra-estruturais objetivando o fornecimento de externalidades apropriadas pelo sistema e a facilidade de uso dos novos produtos e processos em todo lugar; g) a tendência das novas firmas pequenas e inovadoras entrarem nos ramos em expansão rápida da economia, e, em alguns casos, de iniciar setores de produção inteiramente novos; h) uma tendência das grandes firmas a se concentrarem, seja por crescimento seja por diversificação;

i) um novo padrão de consumo de bens e serviços e novos tipos de distribuição e de comportamento do consumidor."

Os autores apontam para o fato de que o paradigma tecno-econômico do período pós-guerra - baseado em matérias primas intensivas em energia e petróleo de baixo custo - tem sido substituído durante as últimas duas décadas pelo paradigma tecno-econômico de ICT. Este paradigma, o surgimento do qual se deve principalmente aos custos decrescentes da microeletrônica, "cada vez mais vincula o design, gestão, produção e marketing em um sistema integrado"(11). Também, acarretou numa mudança qualitativa no perfil de habilidades da força de trabalho, que agora tem que estar bastante familiarizada com toda forma de atividade de "manuseio de informação" ("information handling activities").

Como mencionado acima, a relação entre a consolidação do paradigma tecno-econômico de ICT e a desmaterialização potencial de economias nacionais, não foi ignorada. Freeman ${ }^{(12)}$ nota que "o paradigma ICT pode ser moldado e guiado numa direção ambientalmente amigável”, principalmente por meio de: monitoramento e controle de processos de produção mais acurados, que otimizariam a relação input-output; a melhoria de controle de inventário e qualidade; a tendência de miniaturizar os produtos e componentes, utilizando-se assim de quantidades menores de matéria prima; e finalmente, menos ênfase dada ao transporte, dado que a tendência é de mais pessoas trabalharem pelo menos parte do tempo, em casa.

Um dos indicadores mais usado para medir o grau de desmaterialização atingido por um país ou região é o da taxa de consumo de energia. Por exemplo, durante a crise do petróleo, no começo da década de setenta, muitas economias mundiais se submeteram a um tipo de desmaterialização forçada, pois as regulações rigorosas dos governos de muitos países industrializados acarretaram esforços conjuntos de $\mathrm{P} \& \mathrm{D}$ para estabelecer novas práticas e processos técnicos e para adaptar as tecnologias existentes a fim de atingirem reduções substanciais no consumo de energia.

Outro indicador muito usado como barômetro de desmaterialização é aquele da taxa de emissões de poluição. Os defensores da tese de desmaterialização alegam que, na medida em que um país se torne mais rico via industrialização, inevitavelmente lidará com o problema de reduzir a poluição, ou seja, somente atacará o problema de poluição quando estiver rico suficiente ${ }^{(13)}$. Esta idéia encontra expressão formal na agora notória "Environmental Kuznets Curve" (EKC - foi o economista, Kuznets, quem construi a curva), que descreve uma relação entre o PIB e poluição, mostrando que o segundo diminui de acordo com um aumento do primeiro. Vale mencionar que esta curva é muito citada como uma prova científica da tese de desmaterialização dos países ricos pelo Banco Mundial e a Comissão Européia. Também apoiando-se nas "provas" do EKC, um relatório das Nações Unidas afirma que:

"quando um certo nível de renda per capita é alcançado, o crescimento econômico deixa de ser um inimigo do meio ambiente tornando-se um amigo...Por sua vez, este sugere que o meio ambiente não precisa de atenção especial, nem em termos de políticas internas do meioambiente ou de pressão ou auxílio internacional; os recursos podem ser melhor focalizados em crescimento econômico rápido para mudar rapidamente da fase meio ambientalmente não favorável de desenvolvimento para alcançar a fase meio ambientalmente favorável da curva Kuznets." ${ }^{(14)}$

Entretanto, outras pesquisas mostram que, embora detectem-se uma redução em poluição na 
medida em que a renda aumenta, existe uma segunda inflexão no nível de renda alta na qual as concentrações de poluição também aumentam novamente. (Ou seja, a curva muda da forma: de um "U" invertido passa ter a forma de um "N".)

Da mesma forma, as afirmações acerca do que a taxa de produção de materiais "pesados", tais como cimento, está em declínio nos países mais ricos, também têm sido questionadas em várias pesquisas (citadas por Wallace, op.cit.). Estas pesquisas indicam que, apesar de uma tendência geral de queda entre 1966 e 1984, muitos países da $\mathrm{OECD}$, de fato, experimentaram um aumento no consumo de materiais no período entre 1984 e 1990 , assim passando por um processo que representa exatamente o contrário de desmaterialização. Wallace ${ }^{(15)}$ explicita que: "não há evidência que mostre que os países industrializados se transformaram em economias 'pós-industriais' com consumo mais baixo de materiais e energia". Freeman ${ }^{(16)}$ também é cético quanto ao fato de que a desmaterialização perceptível está se tornando uma realidade nos países industrializados. Aponta para o fato que investimentos muito mais pesados e compromissos mais firmes precisam ser feitos em tecnologias alternativas ("verdes"), implicando menos dependência nas inovações incrementais e mais nas radicais, que poderiam levar ao estabelecimento de um paradigma tecno-econômico ainda mais novo, e mais verde. Mas tudo isto leva tempo; como nota Freeman" ${ }^{(17)}$ : "A substituição de prédios e instalações antigos e maquinaria, por novos designs que usem menos energia, é um processo muito demorado".

Em resumo, dúvidas levantadas por Freeman, Wallace e Webster, com relação ao suposto surgimento e consolidação de paradigmas mais desmaterializados e ecológicos de desenvolvimento de sociedades, foram brevemente delineadas acima. Mais especificamente, Freeman ${ }^{(18)}$ enumera aspectos do paradigma ICT que enfraquecem sua capacidade de ser considerado como mais ecologicamente sustentável. Estes aspectos são: o aumento maciço no uso de papel, devido ao acesso ampliado à informação e ubiqüidade no uso de impressoras; ciclos de vida mais curtos de produtos, em particular para bens eletrônicos (a indústria de componentes e periféricos de computadores é um caso exemplar, encorajando os consumidores a descartar partes e periféricos supostamente desatualizados); e, finalmente, os benefícios potenciais das novas tecnologias de comunicação para o meio ambiente provavelmente têm sido anulados pelo aumento do tempo de lazer, o que acarretou uma expansão maciça da indústria de turismo, com encargos substanciais no sistema mundial de transporte, resultando em taxas dramaticamente mais altas de poluição.

\section{OS PAÍSES EM DESENVOLVIMENTO E A DESMATERIALIZAÇĀO}

Como acima notado, a tese de que, na medida em que as economias dos países industrializados se desmaterializam, elas paralelamente "ecologizam", tem ganho respeito durante esta última década, particularmente dentro do Banco Mundial, da Comissão Européia, e das Nações Unidas. Uma implicação supostamente mais otimista desta tese é que aqueles países que "chegaram tarde" à industrialização (os "latecomers") poderiam escolher entre as tecnologias mais maduras e refinadas, e também menos destrutivas ao meio ambiente ("ecologically friendly"), significando que chegariam mais rapidamente a um estado de desmaterialização e, portanto, a uma condição mais ecologicamente sustentável. Embora o Japão, como um país que se industrializou comparativamente tarde, certamente tenha conseguido benefícios ambientais ao adotar tecnologias mais novas e avançadas, a maior parte dos países do terceiro mundo não passou por uma desmaterialização substancial e forçada após a crise de petróleo da década de setenta. Pelo contrário, como Furtado ${ }^{(19)}$ nota, sob pressão de pagar dívidas externas pesadas, estes países de fato aumentaram atividades industriais intensivas em energia (além de implicarem em mais exportação de matéria-prima), com a negligência concomitante dos setores de valor agregado. Young ${ }^{(20)}$ também demonstrou como estratégias industriais no Brasil na década de 80 , ao concentrarem na minimização de déficits comerciais naquela década por meio da intensificação das atividades nos setores de exportação, contribuíram diretamente ao aumento de poluição. A falta aguda de capital entrando no país levou ao uso continuado de maquinaria industrial 
longe de ser de ponta e, portanto, muito ineficiente em termos de uso de energia.

É pertinente aqui lembrar da questão até que ponto as nações industrializadas (e, portanto, potencialmente mais desmaterializadas) continuam dependendo das matérias-primas e bens intensivos em energia manufaturados com mão-de-obra barata nos países menos industrializados. A escola difusionista na história da economia tomou, como ponto de partida, a hipótese do que todas as sociedades foram, num certo momento, subdesenvolvidas, e que o desenvolvimento econômico procederia por uma série de estágios da sociedade tradiconal-agrícola, até a "decolagem" para a maturidade econômica, caracterizada por altos níveis de consumo em massa. (Esta é a famosa teoria de W.W. Rostow, como delineada no seu The Stages of Economic Growth: a non-communist manifesto).

Em contraste, os economistas estruturalistas e os estudiosos da teoria da dependência têm mostrado consistentemente, desde a década de setenta, que esta linha de pensamento oculta o fato de que os chamados países "subdesenvolvidos" continuam nesta posição o tempo todo, travados numa relação de "centro-periferia" com os países mais avançados, os quais, por sua vez, dependeriam da manutenção da posição subordinada dos países produtores de matérias-primas. Em resumo, os estruturalistas e teóricos da dependência enfatizaram que todos os países fazem parte do mesmo sistema econômico mundial e integrado e que a lógica do sistema depende da preservação da relação centro-periferia, e que está dentro dos interesses dos países ricos que uns países nunca consigam alcançar ("catch up") os outros ${ }^{(21,22)}$.

Webster apontou que a tese de Bell de uma sociedade desmaterializada e pós-industrial também tem o erro do pensamento teleológico semelhante àquele dos difusionistas. Ou seja, Bell adere ao pressuposto subjacente que todas as sociedades passarão por um movimento que vai de um estado pré-industrial ao industrial até o pós-industrial. O problema com tal tipo de pensamento é que pode gerar passividade, como Webster ${ }^{(23)}$ coloca:

"Como conseqüência disso, de alguma forma, as pessoas não têm que fazer nada, e nem se preocuparem com os problemas que encontram nas suas sociedades - injustiças, desigualdades, a inconstância ou obstinação de seres humanos - porque a lógica da história garante que se movem inexoravelmente para frente e para cima na direção de uma ordem melhor e mais desejável."

Esta colocação nos lembra um pouco daquela acima mencionada de que nenhuma política explicitamente ambiental é necessária para lidar com problemas ambientais; é só preciso ter fé no ideal de que ostatus quo econômico eventualmente resolverá tais problemas.

Vários autores ${ }^{(24,25,26,27)}$ mostraram que o cenário centro-periferia está muito vivo neste mundo globalizado. Por exemplo, apesar de crenças bem difundidas acerca da natureza intrinsecamente democrática de redes, há uma exclusão estrutural delas por parte de muitos países menos desenvolvidos, com a maior parte das redes concentradas nos, e dominadas pelos, países industrializados. Por exemplo, Freeman \& Hagedoorn ${ }^{(25)}$ mostram que, do começo da década de oitenta em diante, mais do que $95 \%$ das alianças estratégicas tecnológicas (consubstanciadas por meio de redes) foram forjadas apenas entre firmas dos países industrializados. Somente uma fração pequena $(2,3 \%)$ destas alianças são entre firmas dos países menos desenvolvidos, mas, principalmente, nos setores de baixo valor-agregado (p.ex. os setores de alimentos, bebidas, vestiário).

\section{"INFORMAÇÄO AMBIENTAL": CARACTERÍSTICAS E ESTRATÉGIAS}

Penteado ${ }^{(28)}$ afirma que a "informação e vivência participativa são dois recursos importantes do processo ensino-aprendizagem voltados para o pleno exercício da cidadania e da consciência ambiental". Percebe-se, então, para cumprir com seus objetivos, o processo de desenvolvimento sustentável necessita de forte suporte informacional, tanto sobre o meio ambiente, quanto sobre alternativas pedagógicas que contemplem os objetivos do desenvolvimento sustentável. O termo "informação ambiental" é às vezes entendido como referindo-se ao conceito de informação científica e tecnológica ambiental, com forte enfoque em informações sobre recursos hídricos, solos, a 
atmosfera, e às vezes, a legislação ambiental ${ }^{(29)}$. O entrelaçamento das trajetórias da área de Ciência da Informação e a consolidação do Big Science do pós guerra explica, em parte, esta ênfase dada à informação científica-tecnológica como recurso essencial para o desenvolvimento. Entretanto, a informação científico-tecnológica, ao aspirar-se às qualidades de "universalidade" do paradigma científico dominante e ocidental, responde mais aos requisitos dos mercados cada vez mais globalizados, do que atende às necessidades locais ${ }^{(30)}$.

O grande desafio é que o armazenamento, processamento e recuperação dessas fontes de informação tão diversificadas são, em si, atividades em potencial altamente intensivas em energia, tempo, mão-de-obra, uma situação que se torna mais complicada ainda pelo fato de que esta massa de fontes de informação está longe de ser sistematicamente integrada. A informação relevante para certos problemas de sustentabilidade, nota Brooks ${ }^{(31)}$, pode surgir e circular livremente dentro do contexto de uma "comunidade pequena de especialistas que não poderia apreciar sua relevância para políticas no contexto no qual inicialmente surgiu. Não é conhecida suficientemente na comunidade científica mais ampla e provavelmente apareceria como uma surpresa do ponto de vista político". Para os inovadores tecnológicos, além de para os policymakers (elaboradores de políticas públicas), o problema, segundo Brooks (op.cit.), é essencialmente do que Herbert Simon denominou como a "gestão de atenção" ("attention management"). Isto significa que o paradigma dominante - seja da última geração de tecnologia, seja de policymaking - estreita a visão, e permite somente baixa receptividade de informação considerada como aparentemente "externa" ao paradigma - um problema muito comum quando se lida com a complexidade das questões multifacetadas do meio ambiente.

As questões ambientais são muito complexas porque, como Brooks (op.cit.) também nota, reconhece-se bastante agora que a geração dos problemas ambientais extrapola a esfera da produção industrial para incluir as "fontes distribuídas" que permeiam a sociedade em geral. $\mathrm{O}$ uso final e descarte de bens de consumo, os sistemas de esgoto, materiais de construção, o setor de serviços em expansão e o uso intensivo de terras para a agricultura - todos afetam o meio ambiente. Vale a pena lembrar que é amplamente aceito que a solução dos problemas ambientais e as estratégias de desenvolvimento sustentável deveriam também extrapolar as esferas governamentais de elaboração de políticas e envolver muito maior participação do público. Como Wynne and Waterton ${ }^{(32)}$ indicam, a ênfase maior na importância das regulações governamentais na Comunidade Européia tem levado a uma situação, na qual existe uma correlação perceptível entre a disponibilidade e disseminação de informação ambiental, e maior participação popular na tomada de decisões em torno de políticas públicas:

"A formalização do papel da informação ambiental, via procedimentos de monitoramento e de reportagem, tem levado indiretamente à maior participação do público que obriga o uso dessas informações nos processos de políticas e abre o processo de regulação a uma comunidade de interessados muito mais ampla e fragmentada."

\section{INFORMAÇĀO E DESENVOLVIMENTO SUSTENTÁVGEL}

Diferentemente do entendimento de informação sobre o meio ambiente, que focaliza mais os fenômenos ambientais de forma especializada e compartimentada, a informação para o desenvolvimento sustentável se caracteriza pela sua abrangência e natureza interdisciplinar, e principalmente pela sua capacidade de provocar uma análise crítica que se reverta numa ação.

Ainda falando do papel da informação para o desenvolvimento sustentável, a participação ativa do indivíduo na construção e representação da realidade é um fato especialmente importante, considerando os papéis potenciais que a informação pode ter no processo de desenvolvimento. Embora seja afirmado freqüentemente que a informação desempenha um papel fundamental no processo de desenvolvimento econômico e social, também sabe-se quão complexo é demonstrar e provar explicitamente esta relação. E esta torna-se mais complexa ainda pelo fato de que a própria percepção, daquilo que seja informação e sua utilidade potencial, é muito orientada pela cultura e pelo local no qual 
foi gerada ou assimilada, o que faz com que a informação para desenvolvimento nos países do hemisfério sul, por exemplo, seja extremamente diferente daquela dos países do norte. Cronin ${ }^{33}$ nota que o potencial que a informação tem no processo de desenvolvimento social depende dos seguintes fatores:

- como a informação é percebida e quais são os pontos principais de ação nas políticas informacionais formais ou informais;

- a cultura predominante (estilos de vida, valores sociais);

- política e ideologia;

- metas sociais explicitadas (p.ex. crescimento econômico vs. justiça distribuitiva);

- a existência de definições consensuais do que constituem benefícios aceitos, socialmente, dos investimentos relacionados à informação;

Este último ponto é bastante relevante lembrando o fato de que a noção de desenvolvimento sustentável engloba questões relativas à qualidade de vida, pois as próprias definições, do que constitui um benefício na forma de um melhoramento na qualidade da vida, são necessariamente definições locais. Cronin (op.cit.) enfatiza ainda que conhecimentos tradicionais e locais são intrinsecamente mais robustos e sustentáveis exatamente porque são permeados pela cultura e pelos valores que os geraram: não têm pretensões de serem "universais" ou "neutros", valores estes, muito almejados no modelo Ocidental de conhecimento "científico", que sempre teve por objetivo principal a ruptura com o senso comum local.

Por que os profissionais de informação deveriam ter conhecimento do seu papel na consolidação de estratégias para o desenvolvimento sustentável? Em um nível, poderíamos dizer que é para reequilibrar a balança histórica, pois, como Spink ${ }^{(34)}$ notou, as raízes históricas da Ciência da Informação podem ser encontradas na busca de remédios tecnológicos ("technological fixes") para lidar com a explosão de informação, e sua aliança com o paradigma neoclássico de desenvolvimento industrial, submetendo-se, implicitamente assim, com mais crescimento econômico e industrialização. Em outro nível, é simplesmente porque a informação tem um papel vital na própria elaboração, execução e consolidação daquelas estratégias de desenvolvimento sustentável. A informação, ao lado de energia e matéria-prima, constitui-se num insumo indispensável aos processos produtivos, sejam eles ecologicamente sustentáveis ou não ${ }^{(31)}$. Deste ponto de vista, a informação é vista como mais um recurso para o processo de produção, e assim variară substancialmente de um contexto para outro, dependendo do processo de produção em questão. Mas a informação também é necessária para o próprio planejamento dessas atividades produtivas, contribuindo não apenas à visão atual da organização inteira, mas também como um componente fundamental ao quadro futuro de longo prazo, como explicitada, por exemplo, em planejamentos estratégicos. Dado que o futuro nunca pode ser concretizado "agora" na forma de energia e matéria-prima, mas somente na forma de meta-informações (planos, projeções, modelos), torna-se imperativo para o bem-estar futuro do planeta que aquela informação seja verdadeira, confiável, acurada. São estas meta-informações que determinarão as fontes futuras de energia, matéria-prima, e informação - ou seja, os insumos dos processos produtivos do futuro. Vale a pena lembrar a observação de Stead e Stead ${ }^{(35)}$ que, diferente dos insumos de energia e matéria-prima das atividades produtivas, que são sempre sujeitos à lei da entropia (que afirma que cada vez que a energia é transformada de um estado para outro, alguma energia disponível para o trabalhoé perdida), a informação pode demonstrar entropia negativa (quer dizer, pode desacelerar o processo entrópico) nas "sociedades que encorajam a expansão contínua e livre de conhecimento e informação"(36).

Num outro nível, a Agenda 21 - o documento no qual se encontram as estratégias para o desenvolvimento sustentável elaboradas na Cúpula do Rio em 1992 - enfatiza a participação das populações locais e regionais como condição sine qua non para a implementação de tais estratégias, e o papel da informação para tal é explicitado no Capítulo 40 do mesmo documento, intitulado "A informação para a tomada de decisão”. Este capítulo enfatiza que, acima de tudo, a informação para o desenvolvimento sustentável tem que ser 
mais efetiva e eficaz em comunicar a complexidade dos indicadores ambientais e o valor do meio ambiente a uma audiência que tem se tornado cada vez mais consciente da gravidade dos problemas ambientais. Isto se traduz na necessidade de implementar sistemas de informação que dêem apoio aos requisitos da comunidade quanto a, por exemplo, saúde, agricultura e educação. Os profissionais de informação têm que se perguntarem (evidentemente, em colaboração com outros profissionais e com o público em geral) até que ponto a informação ambiental, que atualmente vem sendo fornecida, vai de encontro às necessidades existentes e emergentes, e até que ponto é redundante, e onde existem lacunas perceptíveis?

\section{OBSERVAÇÕES FINAIS}

Na década de setenta, numa resposta crítica aos diagnósticos pessimistas feitos pelos autores do relatório Limits to Growth (que, usando modelagem computacional, previu o colapso do sistema mundial até o começo do século 21 , se as populações mundiais continuaram a crescer a taxas atuais), vários pesquisadores ponderaram que, para evitar degradação ambiental em escala global, mais, e não menos, tecnologia seria necessária ${ }^{(37)}$. Contudo, precisaria ser uma tecnologia qualitativamente distinta, uma que trabalhe para o meio ambiente, e que não o danifique, o que implica maior controle de tecnologia, que, por sua vez, implica na necessidade de políticas explícitas e de longo prazo, não somente para controlar a tecnologia, mas para fomentar a dimensão visionária necessária para o desenvolvimento de novas tecnologias "verdes". Pode-se dizer que a mesma se aplica à informação para desenvolvimento sustentável: mais e mais será necessária para lidar com a complexidade das questões ambientais, mas, as formas que a informação é coletada, gerenciada, processada e armazenada, além de disseminada, exigirão estratégias inovadoras e poupadoras de energia. Isto também exige a elaboração de políticas de informação - em níveis nacionais e institucionais - que incorporem os desafios colocados pela missão de desenvolvimento sustentável.

Como foi discutido aqui, declarações sobre o aparecimento de uma sociedade de informação que é, portanto, desmaterializada, não se constituem numa garantia suficiente para a sobrevivência ecológica do planeta. A própria consolidação do paradigma ICT pode, em si, contribuir muito na direção de fomentar formas de viver e trabalhar que sejam ambientalmente sustentáveis, porém como Freeman ${ }^{(38)}$ advertiu, para assegurar desenvolvimento sustentável de longo prazo, mais uma mudança paradigmática provavelmente será necessária, mas lembramos que teria que ser uma que não mantenha o atual desequilíbrio entre os países dos diferentes hemisférios. Assumindo que a interpretação e uso de informação traz uma mudança de configurações de conhecimento (em níveis individuais, regionais, nacionais e internacionais) necessárias para esta mudança de paradigma, é pertinente fechar com as observações de Francisco Sagasti ${ }^{(39)}$ sobre o ponto:

"O papel que o conhecimento agora tem no processo de desenvolvimento é tão crítico que o desenvolvimento em si poderia ser redefinido em termos da capacidade de gerar, adquirir, disseminar e utilizar o conhecimento, ambos o moderno e o tradicional. A presença ou ausência desta capacidade constitui-se num marco divisor crucial entre as nações desenvolvidas e aquelas em desenvolvimento."

\section{REFERÊNCIAS BIBLIOGRÁFICAS}

1. WEBSTER, F. Theories of the Information Society. New York: Routledge, 1995, p.38.

2. HOBSBAWM, E. Era dos extremos : o breve seculo XX, 1914-1991. Sao Paulo: Companhia das Letras, 1995, p.25.

3. SACHS, I. Estratégias de transição para o século XXI. In BURSZTYN, M. (org.) Para pensar o desenvolvimento sustentável. São Paulo: Brasiliense, 1993, pp. 29-56.

4. PENTEADO, H.L., Meio ambiente e formação de professores. São Paulo: Cortez, 1994.

5. RIBEIRO, G.L. Ambientalismo e desenvolvimento sustentado: ideologia e utopia no final do século XX. Ciência da informação, 21, 1992, p.23-31.

6. MiTCHAM, C. The concept of sustainable development: its origins and ambivalence. Technology in Society v.17, n.3, 1995, pp.311-326. 
7. TIJMES, P.; LUIJF, R. The sustainability of our common future:an inquiry into the foundations of an ideology.Technology in Society, v.17, n.3, 1995, pp.327-336.

8. FORAY, D.; GRÜBLER, A. Technology and the environment: An overview. Technological forecasting and Social Change, 53, 1996, p. 3- 13 .

9. FREEMAN, C.; PEREZ, C. Structural crises of adjustment, business cycles and investment behaviour. In DOSI, G.et.al.(Eds.) Technical change and economic theory. New York: Pinter, 1988, pp.38-65.

10. Idem, p.59.

11. Idem., p.60.

12. FREEMAN, C. The economics of hope: essays on technical change, economic growth and the environment. New York: Pinter, 1992, p.203.

13. WALLACE, D. Sustainable Industrialization. London: Royal Institute of International Affairs \& Earthscan Publications, 1996.

14. citado em idem. p. 28.

15.idem. p.31.

16. FREEMAN, C, 1992,op.cit.

17. FREEMAN, C, 1992,op.cit.,p.193.

18.ibid.

19. FURTADO, A. Opções tecnológicas e desenvolvimento do terceiro mundo. In C. Cavalcanti (Ed.). Desenvolvimento e natureza: estudos para uma sociedade sustentável. São Paulo: Cortez., 1995, pp.256-275.

20. YOUNG, C.E.F. Industrial pollution and exportoriented policies in Brazil. Revista Brasileira de Economia, v.52, n.4, 1998, pp.543-561.

21. CARDOSO, F.H. As idéias e seu lugar: Ensaios sobre as teorias do desenvolvimento. Petrópolis: Vozes, 1993.

22. CANO, W. (1994). Reflexões sobre o Brasil e a nova (des)ordem internacional. 3. ed.. Campinas: Editora da Unicamp.

23. WEBSTER, F.op.cit. p.32.

24. ERNST, D. Network transactions, market structure and technology diffusion - implications for south-south co-operation. In L.K. MYTELKA (Ed.), South-south co-operation in a global perspective. Paris: OECD, 1994.pp. 89-124.
25. FREEMAN, C.; HAGEDOORN, J. Catching up or falling behind: patterns in international interfirm technology partnering. World Development, 22, 1994, p.771-780.

26. PEREZ, C. Technical change and the new context for development. In L.K. MYTELKA(Ed.),op.cit., p.55-87.

27. PEREZ, C. La modernización industrial en América Latina y la herencia de la sustitución de importaciones. Comércio Exterior, 5, 1996, p.347-363.

28. PENTEADO, H.L. Meio ambiente e formação de professores. São Paulo: Cortez, 1994.

29. FERNANDES, L.R.R.M.; SKOLIMOVSKI, E.B. Informação ambiental: uma lacuna sendo preenchida no Brasil. Ciência da informação, v21, n.1, p.46-51, jan./abr. 1992.

30. COSTA, L.S.F., FURNIVAL, A. C.; KRAUSS, P.P. Informação para Educação Ambiental: proposta para criação de um centro de referência.Ciência $e$ desenvolvimento sustentável. São Paulo: Instituto de Estudos Avançados, USP, 1997, pp. 301-309.

31. BROOKS, H. The problem of attention management in innovation for sustainability. Technological Forecasting and Social Change, 53, 1996, pp. $21-6 . p .23$

32. WYNNE, B.; WATERTON, C. Public information on the environment: the role of the European Environment Agency. In P. LOWE, P.; WARD, S. (Eds.), British Environmental Policy and Europe. London \& New York: Routledge, 1998, pp.119-137.p.125-6.

33. CRONIN, M. Social development and the role of information. The New Review of Information and Library Research, 1995, p.23-37.

34. SPINK, A. Information and a sustainable future. Libri, 45, 1995, 203-208.

35. STEAD, W.E.; STEAD, J.G.Managementfor a small planet: Strategic decision making and the environment. Thousand Oaks, CA: Sage Publications, 1996.

36.idem., p.52.

37. FORAY, D; GRÜBLER, A, op.cit. .

38. FREEMAN, C. The greening of technology and models of innovation. Technological forecasting and Social Change, 53, 1996, p.27-39.

39. SAGASTI, F.R. Knowledge and development in a fractured global order. Futures, 27, 1995, p.591-610. 